\title{
CO2 IOR in the Szank Field Using CO2 from Sweetening Plant
}

\author{
Remenyi L., Szittar A., Udvardi G.
}

MOL, Hungary

\begin{abstract}
Copyright 1895, Steering Committee of the European IOR - Symposium.
This paper was presented at the 8th. European IOR - Symposium in Vienna, Austria, May 15 - 17, 1996

This paper was selected for presentation by the Steering Committee, following reviow of information contained in an abstract submitted by the author(s). The paper, as presented has not been reviewed by the Steering Committee.
\end{abstract}

\section{Abstract}

Field scale $\mathrm{CO}_{2}$ EOR operations started in 1972 in Hungary. Partially miscible EOR recovery was completed in the sandstone reservoirs of Budafa and Lovászi fields and recovery by artificial $\mathrm{CO}_{2}$ gas cap has been accomplished in the carstic/cavernous limestone reservoir of the Nagylengyel field. A sweetening plant was built in the area between the Danube and Tisza to utilize the bigh $\mathrm{CO}_{2}$ content natural gases. The "byproduct" of this plant is $\mathrm{CO}_{2}$ gas. Using this gas immiscible $\mathrm{CO}_{2}$ EOR operation was realized in the SE zone of the Szank field. The injection of $\mathrm{CO}_{2}$ started in 1992. The former production experiences could well be utilized during the $\mathrm{CO}_{2}$ recovery.

The paper presents the production technology, the results, the plant facilities, introduces the experiences gained during the production and gives a summary of Hungarian experiences in the field of EOR recovery projects and reservoir management.

\section{$\mathrm{CO}_{2}$ EOR recovery operations in $\mathrm{SW}$ Hungary}

EOR research and investigations started as early as in the 50's in Hungary. Pilot plant experiments started in the 60's with the injection of carbonated gas made of flue gas of boilers.
A high $\mathrm{CO}_{2}$ content natural gas reservoir has been discovered under the Budafa oil field (Budafa deep horizon) which rendered possible wide-spread use of $\mathrm{CO}_{2}$ EOR methods in SW Hungary (1), (2), (3).

Field-scale EOR operations started between 1969 and 1981 based on this high pressure gas reservoir containing an $81 \%$ by mole $\mathrm{CO}_{2}$ concentration natural gas. The reservoir rock of the fields is sandstone and the $\mathrm{CO}_{2} \mathrm{EOR}$ is of partially miscible type.

A special segregation recovery method has been developed in field-scale for the Nagylengyel field. The reservoir rock is carstic limestone. Pilot plant experiments started in 1979 and the so-called "recovery by artificial $\mathrm{CO}_{2}$ gas cap" method is used in field-scale sinde 1988 (4). It is an extraordinary luck by the nature of things that the 150 bar wellhead pressure of the Budafa deep horizon rendered possible the operations without compressor (5).

Approximately 2.5 million ton additional oil was produced till the end of February 1995 from the Budafa, Lovászi and Nagylengyel fields by $\mathrm{CO}_{2}$ EOR method. The production is in its final stage in the Budafa and Lovászi fields, but in Nagylengyel the recovery by artificial $\mathrm{CO}_{2}$ gas cap will probably continue after 2000 , too. 
The mechanism and experiences of $\mathrm{CO}_{2}$ EOR operations in SW Hungary

It is a basic fact from recovery technology point of view that the natural parameters of the sandstone reservoirs (reservoir pressure and -temperature), the reservoir fluid and the composition of the given carbonated natural gas do not render possible the establischment of dynamic miscibility.

\section{Stages of recovery:}

increase of reservoir pressure by injection of carbonated natural gas from 30 bar to $110 \mathrm{bar}$; water flooding; depletion.

The high gas saturation of the layers resulted in a favourable volumetric flood efficiency. However, the initial GOR was high due to the high gas saturation. It was necessary in some cases to restore the pressure of the gas cap, too, and consequently, the specific gas demand increased.

The recovery technology improved continuously as a result of increasing experience. E.g. WAG injection was accomplished in the Lovászi field after increasing the pressure. Similar injection method is used in the Zala-Kerettye layers of the Budafa field by the use of "elastic well pattern". The primary recovery mechanism was the active water drive in the Nagylengyel field. Substantial amount of oil was left behind in closed domes and on the top of the structure during primary recovery. This oil is displaced by establishing an artificial gas cap which results in a gravitational segregation and drainage of this attic oil.

The stages of recovery are:

gas injection; the producing wells operate in this period depending on the position of the oil belt and GOC;

blow-down: all of the producers are in operation;

transfer of the produced gas to other blocks of the field where this process is repeated.
The aim of reservoir management systems was to minimize the specific use of carbonated natural gas and to maximize volumetric flood efficiency in porous sandstone reservoirs. To reach these aims the production wells were produced without limitation until the $\mathrm{CO}_{2}$ concentration of the associated gas reached $65 \%$ by mole. The production rate of the wells was reduced, periodical production or longer shut-in period was prescribed if the $\mathrm{CO}_{2}$ concentration exceeded the limit value mentioned above or if the production GOR reached the 500 cu.m/cu.m limit. The aim of the control in carstic limestone reservoir was to follow the oil belt formed, to maximize the oil production and to minimize the production of free gas both in the period of gas injection and gas blowdown. The wells have and average production rate of $100 \mathrm{cu} . \mathrm{m} / \mathrm{d}$ including water cut, too and are produced after the appearance of oil until the ecpansion of the gas cap results in a sudden increase of the gas production.

\section{Production technology experiences}

The wells of the fields used for primary recovery are utilized in general for $\mathrm{CO}_{2}$ EOR operations, too, together with the necessary modification of functions and the re-completion of the wells. New wells were drilled only if it was absolutely necessary. Special methods had to be used in the Nagylengyel field to well completion where several wells broke down during drilling. The treating of the carbonated natural gas was restricted to the separation of free water, however the pipeline transport to Nagylengyel necessitated the adjustment of the dew point, too. High pressure drying was chosen (by the use of glycerol) so pressure boosting was not necessary (6).

Large-scale facility system was established to the injection of carbonated natural gas and water, to gather and to treat the well effluents and to service- and auxiliary activities (7), (8). 
The corrosion caused by the gas containing $\mathrm{H}_{2} \mathrm{~S}$, too, was very severe in the first period. However, the highly efficient gas processing reduced significantly these problems.

Quality and quantity considerations caused and cause problem for the injection water in Budafa and Lovászi field; the injection water is a mixture of reservoir water and surface waters. The dissolved in water $\mathrm{CO}_{2}$ is a significant source of corrosion in open production facilities when treating well effluents. Hungarian specialists gained widespread experience in the planning, reservoir management, construction and operation of facilitiers of EOR projects, which rendered possible to start new EOR recovery project(s).

Oil and gas production in the area between the Danube and Tisza

The hydrocarbon production started in this area in 1964 (Fig.l). The cumulative production of 35 reservoirs was appr. 4.2 million ton crude oil, 16.9 million cu.m. natural gas and 1.3 million ton gascondensate till the beginning of 1995 . Initially, the gas of the most important field, Szank, was uniform good quality (35-38 $\mathrm{MJ} / \mathrm{cu} . \mathrm{m}$ ) and could be sold without any problem in the area and could be pipelined to the domestic gas network. The prospecting in this area resulted in many new fields, however, the gas of these fields had lower heating value so they could not be put into production.

The specific features of gas reservoirs in the area:

relatively many, separated reservoirs,

little, or medium reserve,

the quality and composition of the gas of individual gas reservoirs differs significantly,

the share of good quality gas sharply decreases, the reservoirs are located in a relatively large area.

The gas quality in the area can be divided into three groups:

- gases of high heating value (35-38 MJ/cu.m.): Szank Miocene gas cap, oil associated gases from Szank-Szank West reservoirs, Szank W II. free gas reservoir, Tázlár-lower Pannonian, Kiskunhalas free gas reservoir;

- gases of medium heating valur (32 MJ/cu.m): Zsana North, Eresztő;

- gases of low heating value (25-30 MJ/cu.m): Tázlár Miocene massive type reservoir, Kiskunhalas NE-N, NE-S oil associated gases, Harka, Jánoshalma, Soltvadkert, Kiskunmajsa-S.

A possible way of selling gases of different quality is to establish a "mixing circuit" which mixes a uniform gas quality from different gases. This mixing circuit was built in 1986 and operated properly" until sufficient quantity and good quality "leading gas" was at disposal and could satisfy the basic and peak demands of the given region. The discovery of the Kiskunmajsa-S field with high reserve but low heating value gas increased gas reserves which can not be utilized by mixing, so new solutions had to be developed to fulfil gas demands.

The construction of a sweetening plant has been decided to ensure the gas quality prescribed by the standard and to sell the gas. The aim of this plant was to remove $\mathrm{CO}_{2}$ from natural gases.

\section{Theorethical questions of $\mathrm{CO}_{2}$ removal from natural gases}

Several processes are known to remove $\mathrm{CO}_{2}$ from natural gas. The choice among them is influenced by the quality and parameters of input gas and the prescribed parameters of output gas. 
In our case the natural gas contains $5-6 \%$ by mole of $\mathrm{N}_{2}$, so it was necessary to reduce the $\mathrm{CO}_{2}$ content of the output gas under $2 \%$ by mole (removing the sour component the hydrocarbon natural gas enriches in nitrogen). The solvent technologies are favourable under such conditions. Most of the offerts for the sweetening plant proposed the tertiary amine process. The "a-MDEA" (BASF licene) technology has been chosen.

\section{The sweetening plant}

The scheme of the technology: the gas contacts in counterflow with the solvent in the absorber. The gas enters on the bottom of the tower and leaves it on the top. This gas containing $\max .2 \%$ by volume $\mathrm{CO}_{2}$ can be pipelined after processing. The a-MDEA entering on the top of the tower will be saturated with $\mathrm{CO}_{2}$ and leaves the tower on the bottom. The regeneration of the solvent - removal of $\mathrm{CO}_{2}$ - happens in three pressure stages and by heating. The liberated $\mathrm{CO}_{2}$ will be compressed in thress pressure stages (fitted to the pressure of desorbers) to 56-58 bar. After the third stage the $\mathrm{CO}_{2}$ gas in treated with TEG to set the necessary $18^{\circ} \mathrm{C}$ dew point and is compressed by the fourth stage compressor to the EOR injection pressure (180 bar).

\section{The technical parameters of the facility:}

Input gas stream: 40 thousand cu.m/h natural gas

$17-26 \% \mathrm{CO}_{2}$ content

55-60 bar pressure

Output gas stream: 33-29,6 thousand cu.m/h sales gas $\left(\mathrm{CO}_{2}\right.$ content $\max .2 \%$ )

50-55 bar pressure

$7-10$ thousand cu.m/h

$95 \%$ purity $\mathrm{CO}_{2}$ at 180 bar

The carbon dioxide is a by-product of the enrichment process which can not be vented into the atmosphere any more because of environmental assumptions.
It seemed obvious to use this gas for EOR purposes based on the experience gained in SW Hungary and, simultaneously the environmental problems would also be eliminated.

\section{The Szank field}

The Szank oilfield has been explored between 1964 and 1975. It is a massive type reservoir with great gas cap and is superimposed on an elevated block of the basement.

The reservoir rock is middle Miocene limestone and calcareous sandstone, the porosity is $10-25 \%$, the permeability - 10 $500 \times 10^{-3} \mathrm{um}^{2}$. The lithological variability of the Miocene formations is extremely high both in horizontal and vertical direction so the hydrodynamic interconnections are very limited in some areas. The reservoir was subdivided into several zones because of the above mentioned, the different phase boundaries, the different crude oil composition and the different reservoir pressure depletion:

- the NW zone interconnected with the great gas cap,

. the SW zone nterconnected with the great gas cap, too,

the NE zone with little gas cap having a limited interconnection with the central gas cap, and

the $\mathrm{SE}$ zone which can well be separated from the gas cap and the other zones.

The manner of operation of the different zones is defined first of all by their position related to the gas cap and the edge water body. The reservoir has an overpressure. The reservoir parameters and the properties of reserevoir fluid are summarized in Table 1.

The NE zone has a little gas cap and has a limited hydrodynamic interconnection with the central big gas cap through the water body and the gas cap. Water drive is the basic production mechanism of this zone. 


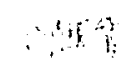

\section{Experience of the primary recovery}

The NE and SE flank of the Szank field became suitable for $\mathrm{CO}_{2}$ EOR operation. The NE zone has a gas cap, the SE zone has no gas cap and is independent from hydrodynamic point of view. The crude oil of the SE zone is undersaturated, its bubble point pressure is 172 bar and $R_{\text {si }}=79,3$ cu.m/cu.m. The initial reservoir pressure was $244 \mathrm{bar}$, the reservoir temperature was 113 centigrade on the reference plane in $1756 \mathrm{~m}$ s.s.l. The SE zone of the field would give probably $90 \%$ of the additional oil. The SE zone based on production past data can be divided into two areas: Middle and South.

\section{Cumulative production data of the SE zone (end of 1992):}

Area $\begin{gathered}\text { Oil } \\ \begin{array}{c}\text { producti } \\ \text { on } \\ 10^{3} \\ \text { cu.m. }\end{array}\end{gathered} \begin{gathered}\begin{array}{c}\text { Recov } \\ \text { ery }\end{array} \\ \text { producti } \\ \text { on } \\ 10^{3} \\ \text { cu.m. }\end{gathered}$
ressure
Middle
SE

horizontal well Szk-145 were drilled to improve the recovery.

\section{Extention of the geological knowledge and refinement of the reservoir model}

The geological re-evaluation of the zone was urged by the fact that the control of reserve by material balance method indicated increasing reserve with time. The work started in 1986. The analyses have shown that the SE zone has not been confined from the east and the reserve of this east zone is greater that calculated earlier. To complement research, new 2D seismic line measurements were accomplished in 1989 and in 1991 the whole area was surveyed by $3 \mathrm{D}$ measurements.

The wells drilled to complete the well pattern of $\mathrm{CO}_{2}$ recovery proved the assumptions based on seismic data. The upto-date 3D seismics and a horizontal well (260 $\mathrm{m}$ horizontal section) has been also utilized in the Szank $\mathrm{CO}_{2}$ EOR.

\section{Laboratory investigations}

The aim of laboratory investigations was to obtain informations about the character of processes initiated by $\mathrm{CO}_{2}$ injection and to determine the parameters of the crude oil/natural gas $/ \mathrm{CO}_{2}$ system.

These investigations included:
the determination of minimum miscibility pressure (MMP),
. modelling of the process in a PVT cell,
. displacement tests.

The measured MMP was 250 bar which is slightly higher than the initial reservoir pressure and 50 bar higher than the abandonment pressure of the primary recovery. The PVT measurements indicated a substantial vaporization of the crude oil under reservoir conditions caused by $\mathrm{CO}_{2}$. 
PVT measurements have shown that complete miscibility can be approached but can not be reached. Consequently, the $\mathrm{CO}_{2}$ EOR has been planned for immiscible displacement.

\section{Projected recovery process}

The exprerience gained in SW Hungary has been taken into account in the planning of Szank $\mathrm{CO}_{2}$ EOR

The planned $\mathrm{CO}_{2}$ EOR for Szank $\mathrm{SE}$ is characterized by:

The gas is injected on the top of the structure. The gas injection rate is determined so that the gas front stabilizing effect of gravity forces may prevail, the flow velocity will be less than the critical one. As there is no mobile water on the top of the structure, the volumetric sweep efficiency of the $\mathrm{CO}_{2}$ gas increases. The pressure increase with gas injection increases oil swelling and vaporization and reduces oil viscosity. The heterogenity of the reservoir may lead to local pressure increase and in these locations the displacement may approach dynamic miscibility. A part of the residual oil vaporizes in the pore space where gas cap is formed due to the gas injection and this oil can be recovered during the gas recuperation. The planned technology has two main phases:

- gas injection

- recovery.

The displacement by $\mathrm{CO}_{2}$ and the segregation effect of the gas cap also will be effective in the Szank prorus/fractured carbonate reservoir. The reservoir management has to take into account both the $\mathrm{CO}_{2}$ concentration of the associated gas and the rapid increase of production GOR The aim of the control of gas injection into individual wells is to maintain a uniform GOC.

The additional oil recovery and production parameters are shown in Fig.2. The GOR increment after 2002 is the consequence of gas cap blow-down. The effect of $\mathrm{CO}_{2}$ injection appears mainly in the reduction and stabilization of water cut.

The gas injection has started in 1992, its planned duration is 11 years and will terminate at the end of 2002 . The producton starts in 2003 and will terminate probably in 2013. The cumulative volume of injected gas will be 734,4 million cu.m.

The characteristic features of injection and recovery:

Injection

Increase of reservoir

Swelling of reservoir

Vaporization

Gasing of production

The initial results of $\mathrm{CO}_{2}$ Table 2

The gas injection started in July 1992 into the SE zone of the reservoir. $90 \%$ of the $\mathrm{CO}_{2}$ gas has been injected into the $\mathrm{SE}$ reservoir. The annual injected gas volume is less than planned. The main reason of this lag was that the sweetening plant has been operated to fulfil sales gas requirements and so, the volume of $\mathrm{CO}_{2}$ differed from the prescribed quantity. The effect of injected $\mathrm{CO}_{2}$ can be observed in the top of the SE zone, mainly because of the breakthrough of $\mathrm{CO}_{2}$. The production parameters are:

$\begin{array}{ccccc}\text { Year } & \begin{array}{r}\text { NP, } \\ \text { cu.m. }\end{array} & \begin{array}{c}\text { GP, } \\ 106 \\ \text { cu.m. }\end{array} & \begin{array}{c}\text { Water } \\ \%\end{array} & \begin{array}{c}\text { GOR, } \\ \text { cu.m } / \text { cu }\end{array} \\ 1992 & 24363 & 2,011 & 67,4 & 82,5 \\ 1993 & 26214 & 3,051 & 69,4 & 116,4 \\ 1994 & 25352 & 5,353 & 71,4 & 211,1\end{array}$

The first result of $\mathrm{CO}_{2}$ EOR operation was to maintain the production on a constant level, although the production of the four new wells contributed to it. Two "huff and puff" experiments were made in the NE zone. 
The experiments were not successful but in the vicinity of the injection wells some wells showed oil inflow.

\section{Injection and production system}

The gas leaving the sweetening plant has a 18 centigrade dew point and 180 bar pressure. This treated $\mathrm{CO}_{2}$ gas goes through a ND 100 and rated pressure 210 bar pipeline to the injection and production facility of the Szank SE reservoir. The components of the reception unit are the separator and the heat exchanger. The $\mathrm{CO}_{2}$ gas is injected into the injection wells after individual metering. The volume of gas injected into the individutal wells is controlled by throttle gate valve. The production wells are flowing or are pumped. The gathering, separation and processing of the well stream(s) is traditional. The separated oil associated gas - with increasing $\mathrm{CO}_{2}$ concentration with time - is fed back to the sweetening plant as feed gas. If the $\mathrm{CO}_{2}$ concentration of this gas exceeds $80 \%$ then it is compressed and reinjected into the reservoir. The scheme of technology is shown in Fig.3.

\section{Experience of the preliminary operation of sweeting plant}

The preparation, evaluation, report on tenders and the construction was directed by expert teams. The operator took part in the work of the teams from the very beginning. Larger and smaller problems arise even today, but the sweetening technology ensures the necessary parameters both for the hydrocarbon and $\mathrm{CO}_{2}$ gas. The technical operation is satisfactory, too. Serious corrosion problems arose in the inhibitor elution system of the feed gas. The selection of proper material and exchange of the unit could solve this problem.

\section{Operation experience of the $\mathrm{CO}_{2}$ injection system}

The $\mathrm{CO}_{2}$ injection system operates troublefree.
Serious corrosion problems occured in the gas- and liquid treating units of the production facilities. Corrosion prevention was solved by inhibitor dosage and coatings. Several measurements were performed to choose the proper solution and a corrosion monitoring system has been established. The liquid pipeline between the gathering station and main gathering station has been lined with plastic pipe to prevent corrosion damage.

\section{General experiences of EOR operations}

EOR has a more than thirty year past in Hungary. The successes and unsuccesses offered several general experiences. It is attempted to summarize them according to the general basic principles published in the JPT Dec. 1994 (9). Determination of the aim, planning, realisation, monitoring and control of results and during the operation modification of EOR projects necessitates an integral reservoir management. This management system requires the perfect knowledge of the reservoir, has to take into account the economic, political conditions and the environment, the human and technical resources and the technical culture of the company. The integrated reservoir management must be realized with the coordinated team work of the specialists of geosciences (geology, geophysics), reservoir engineering, drilling and well completion and plant operation. No doubt, these statements are valid in general for the reservoir management system of every field, but particularly for EOR projects because of their greater uncertainty. EOR makes necessary and indispensable the team work and the first unsuccess enforce it if the project as a whole was not properly organized.

The geology and petrophysics have especially great importance in the planning of EOR. The domestic experience indicates, too, that new geological evaluation and significant modification of the geology was necessary for the planning of EOR. 
The production history of the given field must be thoroughly processed, analyzed and interpreted by the reservoir engineer planning an EOR project. The reservoir model and production technology have to be elaborated in close team work by the geologist and the reservoir engineer. The simulation and use of new technologies (e.g. horizontal drilling) is necessary and economical for minor fields, too. The proper planning, construction and operation of well equipments and surface facilities contributes also to the success of a given EOR project.

A continuous dialog must run on between reservoir- and production engineers, because new and unexpected events always may occur even if the project is planned with utmost care and several versions.

Exonomic optimization is a crucial field of EOR projects. The aim of EOR is profit which is determined by forecasted production, investment, overhead costs and financial conditions, e.g. tax. The continuous economis optimization needs a continuous and detailed cost follow-up.

The economic results, or the change of economic and financial environment, e.g. change of the oil price, needs change of the technology which may lead to necessary simplification, changes and compromises.

It is absolutely necessary to take into account the special technical, economic and human factors of abandonment following the production in the planning of EOR as the field is in the final stage of production.

\section{Summary and conclusions}

The operation experience of EOR is SW Hungary rendered a firm base to plan and realize the Szank $\mathrm{CO}_{2}$ EOR facility.

The application of new scientific and technical achievments increases the efficiency of EOR projects.

. EOR operations need the re-evaluation of the geology of field and a through engineering preparatory activity.

The reliable operation of the $\mathrm{CO}_{2}$ gas source - in this case the sweetening plant is indispensable.
The solution of production technology problems is decisive in EOR operations.

. EOR needs an integrated reservoir management and an effective team work.

. The economic environment in EOR operations is decisive.

\section{Acknowledgement}

Authors want to acknowledge the management of Hungarian Oil and Gas Co. of the permission to publish this paper and László Fehér petroleum engineer for the collection of field experiences.

\section{References}

1. S. Doleschall, A. Szittár, G. Udvardi: Review of the 30 Years' Experience of the $\mathrm{CO}_{2}$ Improved Oil Recovery Projects in Hungary (Presented at the 1992 SPE Intl. Meeting on Petroleum Engineering held in Beijing, China, March 24-27.) SPE 22362

2. G. Németh, J. Pápay, A. Szittár: Experience with $\mathrm{CO}_{2}$ EOR process in Hungary Revue de Institut Francois du Petrole Vol. 43, No.6. Nov-Dec. 1988.

3. J. Pápay, Z. Gombos: Enhanced oil recovery in Hungary KÖOLAJ ÉS FÖLDGÁZ 27. (127) évf. 12. szám, 1994. december

4. Z. Bíró, A. Szitár: $\mathrm{CO}_{2}$ gas cap field test in Karst type reservoir of Nagylengyel field. Fifth European Symposium on Improved Oil Recovery Budapest, 25-27 April 1989

5. G. Udvardi: Production technical experience of exploitation by means of Carbon dioxide Int. Symp. on $\mathrm{CO}_{2}$ Enhanced Oil Recovery Budapest, 8-11 March 1983

6. Géza Udvardi, László Gerecs, Yasuo Ouchi, Fumio Nagakura, Edward A. Thoes, Charles B. Wallace: $\mathrm{CO}_{2}$ dehydration scheme aids Hungarian EOR project Oil \& Gas Journal, Oct 22. 1990.

7. G. Udvardi: $\mathrm{CO}_{2}$ EOR facilities in Hungary: Field tests with respect to operation and corrosion problems Fifth European Symposium on Improved Oil Recovery Budapest, 25-27 April 1989

8. D. Magyari, G. Udvardi: Operation know-how obtained by production units of Nagylengyel $\mathrm{CO}_{2}$ gas cap recovery. Oil \& Gas Journal, July 22.1991. 9. Abdus Satter, SPE, James E. Varnon, SPE and Muu T. Hoang: SPE, Texacolnc.: Intergrated Reservoir Management JPT Dec. 1994. 


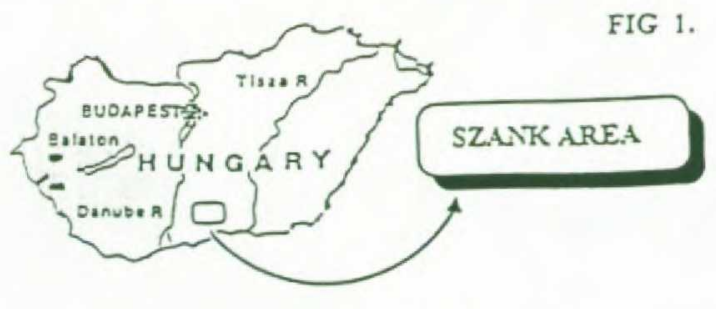

LOCATION OF SZANK AREA
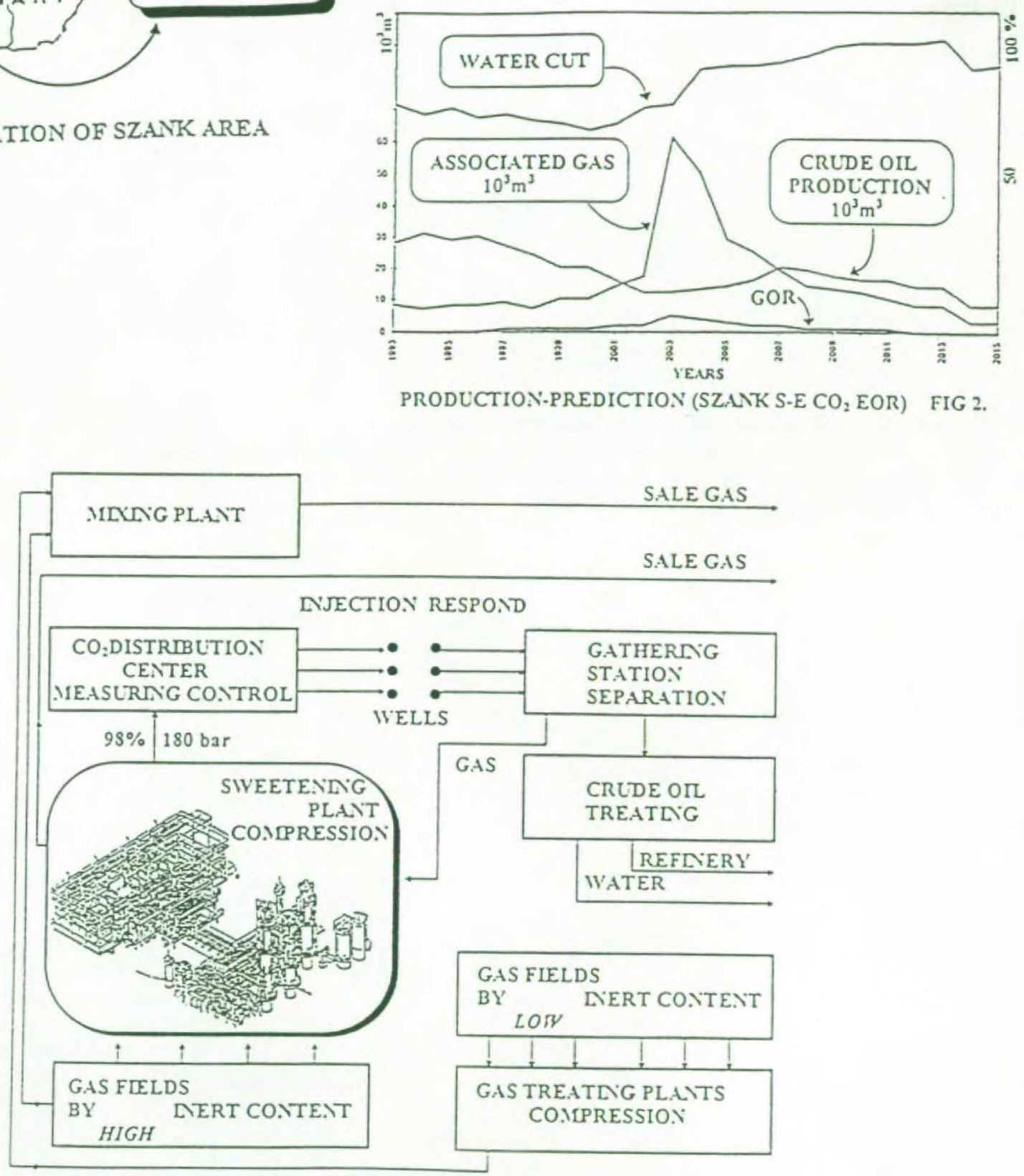

GE.IERAL SCHEIIE OF SWEETENLIG \& $\mathrm{CO}_{2}$ EOR FACIITIES SZANK AREA

FIG 3.

RESERVOIR PARAMETERS TABLE 1.

- O.O.IP

$5 \cdot 10^{6} \mathrm{~m}^{3}$

- NitLla Reservoir presslre 244 bar

- POROSITY LLIESTONEBRECCLAMETAMORPHITE

- PERMEABILITY

- oil deNsity

(CNDERSATLRATED)

- solutiongas/oil ratio

- oll Viscosity

- irassive tYPE RESERVoIR (LIIESTONE-BRECCI.AMETAMORPHITE)

- partial edGe water-drive $10-300 \mathrm{md}$ $0,85 \mathrm{t} / \mathrm{m}^{3}$ $79 \mathrm{~m}^{3} / \mathrm{m}^{3}$
FIELD RESULTS

TABLE 1.

- CO, LNJECTION COMNENCED AT THE EXD OF JLLY' 1992 ALONG THE HIGHEST STRLCTURAL POSITION AT PINCH LLNE OF THE MIOCENE ROCK

- NUMBER OF LJJECTION WELLS:
- NUMBER OF PRODLCTION WELLS: 18 2,9-7,6 $\mathrm{mPa} \cdot \mathrm{s}$ STATUS (1ST OF JAN 1995)

D VOLLME OF LNJECTED CO: GAS $\quad 82.10^{6} \mathrm{~m}^{3}$ 口 RECOVERED OU AVERAGE GOR PRESSLRE LICRENIENT $\sim 200 \mathrm{~m}^{3 /} \mathrm{m}^{3}$ $\sim 6$ bar 